\title{
SERIES NO. 2 \\ ANALYSIS OF $\beta$-CAROTENE AND LUTEIN IN SOME LEAFY VEGETABLES AND EFFECT OF COOKING ON SERUM VITAMIN A FORMATION FROM ALTERNANTHERA SESSILIS (SINH. MUKUNUWANNA)
}

\author{
U. G. CHANDRIKA ${ }^{1 *}$, E. R. JANSZ ${ }^{1}$ and N. D. WARNASURIYA ${ }^{2}$ \\ ${ }^{1}$ Department of Biochemistry, "2Department of Paediatrics, Faculty of Medical Sciences, University of Sri \\ Jayewardenepura, Gangodawila, Nugegoda.
}

(Accepted: 29 November 2004)

\begin{abstract}
Abstact: Vitamin A deficiency is a public health problem in Sri Lanka. Although consumption of leafy vegetables has been advocated to alleviate this problem, there is no data on the analysis of carotenoids of leafy vegetables by High Pressure Liquid Chromatography (HPLC). This study reports the HPLC quantification of carotenoids beneficial to health (lutein and $\beta$-carotene) in mukunuwanna (Alternanthera sessilis), kathurumurunga (Sesbania grandiflora), gotukola (Centella asiatica) and manioc (Manihot esculenta) leaves. The study shows that the level of $\beta$-carotene is higher in manioc $(519.0 \pm 176.8 \mu \mathrm{g} / \mathrm{g}, \mathrm{n}=5)$ and kathurumurunga leaves $(486.7 \pm 39.7 \mu \mathrm{g} / \mathrm{g}, \mathrm{n}=5)$ and lower in the more commonly eaten mukunuwanna $(252.7 \pm 48.2 \mu \mathrm{g} / \mathrm{g}, \mathrm{n}=5)$ and gotukola $(297.4 \pm 21.9 \mu \mathrm{g} / \mathrm{g}, \mathrm{n}=5)$. Of these four types of leaves, manioc showed the highest level of lutein $(1284.9 \pm 63.1 \mu \mathrm{g} / \mathrm{g} ; \mathrm{n}=5)$ and this is worthy of note due to the recent interest in lutein with respect to its protective action on age-related macular degeneration. Studies using Wistar rats have shown that the popular method of eating leafy vegetables (malluma), where the leaf is lightly cooked in the presence of grated coconut leads to high bioconversion of the carotenoids to vitamin $A$ of the vegetable studied (mukunuwanna).
\end{abstract}

Key words: Alternanthera sessilis, $\beta$-carotene, Carotenoids, Centella asiatica, Iutein, Manihot esculenta, Sesbania grandiflora

\section{INTRODUCTION}

Vitamin A deficiency is a nutritional deficiency disorder of public health importance in Sri Lanka. A recent national survey revealed that $36 \%$ of preschool children in Sri Lanka have vitamin A deficiency (serum retinol $<20 \mu \mathrm{g} / \mathrm{dl}$ ). In view of its well-established association with child morbidity and mortality, this is a reason for concern. The main strategy for prevention of vitamin A deficiency in Sri Lanka has been the promotion consumption of vitamin $\mathrm{A}$ rich foods including carotenoids from plant sources. ${ }^{1}$ Yellow and orange-fruits and vegetables, dark green leafy vegetables and non-leafy vegetables have been specially advocated. In addition to provitamin A activity, carotenoids have also been linked with immune-enhancement and decreased risk of degenerative diseases such as cancer, cardiovascular disease, age-related macular degeneration and cataract formation..$^{2-6}$

Green leafy vegetables are the most accessible year-round source of carotenoids. Data on carotenoid content of leafy vegetables is limited ${ }^{7}$ and no studies where carotenoids have been determined by HPLC are available. Unlike fruits, in which the carotenoid composition varies qualitatively and quantitatively, leafy vegetables are known to have a constant qualitative pattern of carotenoids, the principle carotenoids being lutein, $\beta$-carotene, violaxanthin and neoxanthin. ${ }^{8,9}$ $\beta$-carotene is a provitamin A carotenoid to which 100 percent activity is assigned. Lutein is one of the main xanthophyll pigments present in the membrane of macular lutea of the vision apparatus of humans. ${ }^{3}$ Protection against oxidative damage of the lipid matrix and screening against excess radiation are the functions of this xanthophyll in the macular membrane. ${ }^{5}$

Even if pro-vitamin A carotenoids are present, their utilization may not be entirely satisfactory as there are factors that interfere with their bioavailability and bioconversion. The bioavailability and bioconversion of the carotenoids present in the diet depend mainly on the efficiency of their absorption into mucosal cells as well as their conversion to retinol.

This study had two objectives (i) High Pressure Liquid Chromatography (HPLC) quantification of the $\beta$-carotene and lutein of green leafy vegetables commonly consumed by Sri Lankans, namely, mukunuwanna (Alternanthera 
sessilis), kathurumurunga (Sesbania grandiflora), gotukola (Centella asiatica), manioc (Manihot esculenta) leaves (ii) determination of the bioavailability and bioconversion of the carotenoids in mukunuwanna using traditional cooking methods.

\section{METHODS AND MATERIALS}

Isolation of lutein standards by Medium Pressure Liquid Chromatography (MPLC): Kathurumurunga (Sesbania grandiflora) was used as the source of standards because it is easy to extract and has high carotenoid content. To obtain standards, the carotenoids were extracted from the leaves ( $30 \mathrm{~g})$ with cold acetone, partitioned to petroleum ether, concentrated in the rotary evaporator and separated in MPLC column of $\mathrm{MgO}$ (Merck Germany): celite (1:1 activated for $2 \mathrm{~h}$ at $110^{\circ} \mathrm{C}$ ), adjusting the mobile phase, to isolate main carotenoids. ${ }^{6,7}$ The separated carotenoids, which were eluted in petroleum ether containing acetone were washed three to four times with water in a separatory funnel to remove acetone and then dried with anhydrous $\mathrm{Na}_{2} \mathrm{SO}_{4}$. Identification of isolated lutein was carried out by the methods of Rodriguez-Amaya: 9 This involved visible absorption spectra and chemical tests such as acetylation of secondary hydroxy groups with acetic anhydride and methylation of allylic secondary hydroxyl groups with acetic methanol.

An aliquot of standard solution was used to verify purity using HPLC. All aliquots were dried under $\mathrm{N}_{2}$ and immediately before injection, dissolved in $1 \mathrm{ml}$ of HPLC mobile phase, filtered through a $0.22 \mu \mathrm{m}$ PTEF syringe filter (Milipore) and injected into the HPLC. Once the desired purity was verified, the concentration of the pure standards was determined spectrophotometrically, using the following $\mathrm{A}^{\%}{ }_{\mathrm{cm}}$ values: $\beta$-carotene, 2592 in petroleum ether and lutein, 2550 in ethanol. Aliquots of the standards mixture were quantitatively transferred into screw-capped culture tubes, dried under nitrogen and stored in the freezer until use.

Sampling and analysis of the leafy vegetables: Representative samples ( $n=5)$ of each of the four vegetables (mukunuwanna, kathurumurunga, gotukola and manioc) were purchased in Colombo and its suburbs and five, $1 \mathrm{~kg}$ specimens of each of the four vegetables were sampled from the main batch. They were processed immediately as follows. In the case of each specimen, the leaves were finely cut, mixed using a blender, and from this 2-5 g were sampled for analysis. Precautions to avoid artifact formation and losses during the analysis were taken according to procedures adopted previously. ${ }^{9}$

The carotenoids were extracted with cold acetone and partitioned to petroleum ether and the extract concentrated in a rotary evaporator and dried under nitrogen. Immediately before injection, the residue was re-dissolved in $1 \mathrm{ml}$ mobile phase and filtered through syringe filters $(0.22 \mu \mathrm{m}$ PTEF $)$. Each sample $(10 \mu \mathrm{m})$ was injected into the HPLC. Identification of carotenoids was carried out as described previously.

Calculation of carotenoid concentration: Calculation of the carotenoid was performed using standard curves, which were linear over the full range of sample concentration. These curves passed through the origin. A one point calibration

Table 1: Lutein and $\beta$-carotene content (mean \pm SD) of selected green leafy vegetables

\begin{tabular}{lcc}
\hline & lutein $(\mu \mathrm{g} / \mathrm{g}, \mathrm{DW})^{*}$ & $\beta$-carotene $(\mu \mathrm{g} / \mathrm{g}, \mathrm{DW})^{*}$ \\
\cline { 2 - 3 } Mukunuwanna (Alternathera sessilis) & $396.6 \pm 16.2$ & $252.7 \pm 48.2$ \\
Katurumurunga(Sesbania grandiflora) & $497.7 \pm 47.3$ & $486.7 \pm 39.7$ \\
Gotukola (Centella asiatica) & $1014.8 \pm 51.1$ & $297.4 \pm 21.9$ \\
Manioc (Manihot esculenta) & $1284.9 \pm 63.1$ & $519.0 \pm 176.8$ \\
\hline
\end{tabular}

$\mathrm{n}=5$, Each determination is a mean of duplicates; DW- day weight

"All the combinations were significantly different $(p<0.05)$ except for the difference between gotukola and manioc. 
Table 2: Serum retinol concentrations (mean \pm SD) of rats supplemented with different traditional methods of mukunuwanna preparations

\begin{tabular}{|c|c|c|c|}
\hline \multirow[t]{2}{*}{ Method of preparation } & \multicolumn{2}{|c|}{ Serum vitamin A level of rats $(\mu \mathrm{g} / \mathrm{dl})$} & \multirow[t]{2}{*}{ p-value } \\
\hline & Before supplementation & After supplementation & \\
\hline $\begin{array}{l}\text { Mukunuwanna malluma } \\
\text { (Group 1) }\end{array}$ & $4.8 \pm 1.4$ & $25.6 \pm 3.5$ & $<0.001$ \\
\hline $\begin{array}{l}\text { Fried mukunuwanna } \\
\text { (Group 11) }\end{array}$ & $4.5 \pm 1.7$ & $4.4 \pm 2.5$ & 0.926 \\
\hline $\begin{array}{l}\text { Uncooked finely cut mukunuwanna } \\
\text { (Group 111) }\end{array}$ & $4.5 \pm 3.4$ & $4.7 \pm 0.6$ & 0.621 \\
\hline $\begin{array}{l}\text { Control (without mukunuwanna) } \\
\text { (Group IV) }\end{array}$ & $4.2 \pm 2.3$ & $4.5 \pm 0.8$ & 0.571 \\
\hline
\end{tabular}

Each group contains 8 rats $(N=8)$

"finely cut mukunuwanna lightly cooked mixed with grated coconut (average $10.9+0.7 \mathrm{~g} /$ per day were consumed by a rat) bfinely cut mukunuwanna fried in a coconut oil (average $6.3+0.7 \mathrm{~g} /$ day were consumed by a rat)

'Uncooked finely cut mukunuwanna $(10.6+0.5 \mathrm{~g} /$ day were consumed by a rat)

Each measurement was taken in duplicate

Treatment: $50 \mathrm{~g}$ mukunuwanna per $\mathrm{kg}$ body weight rat per day for 4 weeks. This was a supplement on rats feed on a standard diet. $^{11}$

was carried out on each day of analysis. It was verified that this point did not deviate from standard curve. In the present study, different leafy vegetables were quantified by RP-HPLC using external standardization, the calculation being made by one-point recalibration.

Reverse Phase-HPLC (RP-HPLC) for carotenoid analysis: For reverse-phase gradient HPLC, Waters Associates (Milford, MA) pumps (model 515), Shimpak Column, CLC-ODS (M) $\mathrm{C}_{18}$ column, $25 \mathrm{~cm} \times 4.6 \mathrm{~nm}$, rheodyne injection valve, SCL$6 \mathrm{~A}$ system controller and CR-6A recorder, were used. The carotenoid extract $(20 \mu \mathrm{l})$ was injected onto the RP-HPLC column and analysed using acetonitrile: methanol: triflouro acetic acid (58: $35: 7$ ) as mobile phase and detected at $450 \mathrm{~nm}$.

Animal model: Healthy, 4 wks old, male Wistar rats (weight $200 \pm 8.6 \mathrm{~g}$ ) purchased from Medical Research Institute (MRI), were used. They were housed in stainless steel cages under standard conditions. ${ }^{10}$ Rats were randomly divided into four groups ( 8 rats each). Before commencement of the feeding schedule all rats were given standard control diets ${ }^{11}$ (but without added vitamin A) for two wks and blood was collected from the tail vein for determination of serum retinol levels. The rat diets were supplemented separately from feed with different types of mukunuwanna preparations as indicated in Table 2. All rats were fed on standard WHO feed which they consumed normally. Each day in the morning for 4 wks the groups I, II and III received $50 \mathrm{~g} / \mathrm{kg}$ body weight and the control group was given only the standard diet. At the end of $4 \mathrm{wks}$ the rats were anaesthetized with diethyl ether and their blood collected by cardiac puncture using $5 \mathrm{ml}$ disposable syringe. The blood was allowed to clot and the serum separated by centrifugation.

Analysis of serum vitamin A: Serum $(100 \mu \mathrm{l})$ and ethanol $(100 \mu \mathrm{l})$ were mixed vigorously using a vortex mixer. HPLC grade hexane $(600 \mu \mathrm{l})$ was added and the contents mixed again, until the bottom layer was thoroughly extracted. The contents were centrifuged at $2000 \mathrm{rpm}$ for $5 \mathrm{~min}$; the upper hexane layer $(400 \mu \mathrm{l})$ transferred to a small test tube and evaporated under nitrogen. The resultant residue was dissolved in $50 \mu \mathrm{l}$ of 95\% methanol and analysed using RP-HPLC. ${ }^{12}$ RP-HPLC for vitamin A analysis: For reversephase gradient HPLC, Waters Associates (Milford, MA) pumps (model 515), Shimpak Column, CLCODS (M) C18, $25 \mathrm{~cm} \times 4.6 \mathrm{~nm}$, rheodyne injection valve, SCL-6A system controller and CR-6A 
recorder were used. Extracted serum solution $(20 \mu \mathrm{l})$ was injected onto the RP-HPLC column and vitamin $A$ levels were analysed using $95 \%$ methanol as mobile phase and detected at $325 \mathrm{~nm}$. Calculation of the retinol concentration was carried out using standard curves, which passed through the origin to verify linearity over the range of sample concentration and one point calibration was carried out on each day of analysis. Retinyl acetate was also used as an internal standard.

Statistical analyses: Statistical analyses were carried out using SPSS computer software package. Difference between mean values were examined using student's $t$ test.

\section{RESULTS AND DISCUSSION}

The purity of standard calculated as the percentage of the carotenoid peak area of HPLC chromatogram relative to total area was $96 \%$ for lutein and $95 \%$ for $\beta$-carotene. The concentrations of the standards were corrected accordingly. Table 1 shows the carotenoid concentrations of the leafy vegetables calculated by one-point recalibration, the straight-line equation (from the standard curves constructed at the beginning of the study). The chromatographic profiles of carotenoids of green leafy vegetables (mukunuwanna, kathurumurunga, gotukola and manioc) showed that lutein and $\beta$-carotene were the major peaks identified. There is wide variation in lutein in the selected green leafy vegetable, the values ranged from a low of $396 \mu \mathrm{g} / \mathrm{g}$ dry weight (DW) in kathurumurunga to $1284.9 \mu \mathrm{g} / \mathrm{g} \mathrm{DW}$ in manioc, $(p<0.001)$. Of the four leaves studied manioc showed the highest level of lutein content and this is worthy of note due to the recent interest in lutein with respect to age-related macular degeneration. ${ }^{4} \beta$-carotene was the only provitamin A carotenoid detected in these vegetables. Manioc leaf was the richest source of $\beta$-carotene (519.0 \pm $176.8 \mu \mathrm{g} / \mathrm{g})$ followed by kathurumurunga $(486.7 \pm$ $39.7 \mu \mathrm{g} / \mathrm{g}$ ). The difference between these two types of leaves was not significant.The $\beta$-carotene content of manioc and kathrumurunga have been given in the literature was $265 \mu \mathrm{g} / \mathrm{g}$ and $5280 \mu \mathrm{g} /$ g respectively. ${ }^{13}$ Mukunuwanna and gotukola are also good sources of $\beta$-carotene $(252.7 \pm 48.2$ and
$297.4 \pm 21.9$ respectively), but the $\beta$-carotene contents are significantly lower to that of manioc and kathurumurunga $(\mathrm{p}<0.001)$.

It was observed that mukunuwanna malluma ( $10.9 \pm 0.7 \mathrm{~g} /$ day was consumed by a rat) and uncooked mukunuwanna $(10.6 \pm 0.5 \mathrm{~g} /$ day was consumed by a rat) supplements were highly acceptable to rats whereas fried mukunuwanna was consumed to a lesser extent (only $6.3 \pm 0.7 \mathrm{~g} /$ day were consumed by a rat). Serum retinol concentrations of rats supplemented with mukunuwanna malluma (group I) was significantly higher $(\mathrm{p}<0.001)$ than the control group (Table 2). Biological conversion of $\beta$-carotene in mukunuwanna malluma to serum retinol levels was found to be good, indicating good biovailability and bioconversion of the carotenoid. in this vegetable using this method of cooking, which is its most common method of preparation in Sri Lanka. However after 4 wks supplementation with uncooked finely cut mukunuwanna (group III) the serum retinol levels were lower than that of the control group. This finding can be due to the leafy material being uncooked and therefore the matrix of cell walls being subject to less breakage which would reduce carotenoid diffusion out of the leafy materials.

In the case of group II (fried leaf) supplement, rats rejected the leaf and as expected food uptake reflects only the control food and therefore vitamin A levels also show control values. This does not mean that the fried leaf is not a good source of pro-vitamin A to humans who consume the vegetable in this way. This is an example where the animal model is not an adequate substitute for deciding what is best for humans. The results show that the popular method of eating the vegetable in Sri Lanka viz., the "malluma" is a good method of cooking vis-avis vitamin A formation from carotenoid. However, it is necessary to follow up these studies on bioavailability and bioconversion using a human model.

\section{Acknowledgement}

Financial assistance by IPICS research grant no. SRI: 07. 


\section{References}

1. Medical Research Institute Sri Lanka (1998). Report of the survey on vitamin A deficiency status of children in Sri Lanka 1995/96. Publ. UNICEF.

2. Kinskey N. I. (1994). The biological properties of carotenoids. Pure and Applied Chemistry 66: 1003-1010.

3. Kinskey N. I. (2001). Carotenoids as Antioxidants Nutrition 17: 815-817.

4. Landrum J. T., Boné R. A., Joa H., Kilburn M. D., Moore L.L. \& Sprague K. (1997). A one-year study of the macular pigment: The effect of 140 days of a lutien supplement. Experimental Eye Research 65: 57-62.

5. Sujak A., Gabrielska J., Grudzinski W., Borc R., Mazurek P. \& Gruszecki W. I. (1999). Lipid membranes against oxidative damage: The structural aspects. Archives of Biochemistry and Biophysics 37 (2): 301-307.

6. Bendich A. \& Olson J. A. (1989). Biological action of carotenoids. FASEB Journal 3:1927-1932. ILSI press, Washington (1999).
7. Athukorala T.M.S. (1985). Vitamin A and betacarotene content of some common foods. Journal of National Science Council of Sri Lanka 13(2): 187-196.

8. Kimura M. \& Rodriguez-Amaya D. B. (2002). A scheme for obtaining standards and HPLC quantification of leafy vegetable carotenoids. Food Chemistry 78: 389-398.

9. Rodriguez-Amaya D. B. (1999). A Guide to Carotenoid analysis in Foods. ILSI press, Washington.

10. Sumudini K.A.V., Jayasekara S., Jansz E.R. \& Wickramasinhe S.M.D.N. (2004). The neurotoxic effect of palmyrah flour-revisited. International Journal of Food Science and Nutrition 4, In press.

11. Sabourdy M. A. (1998). Breeding and care of laboratory animals. WHO/Lab/88.1.1:45.

12. Bieri J. G., Tolliver T. J. \& Catignani G. L. (1979). Simultaneous determination of $\alpha$ tocopherol and retinol in plasma or red cells by high pressure liquid chromatography. American Journal of Clinical Nutrition 32(21) 43-49.

13. Wickramanayake T. (1980). Foods and Diets. Hector Kobbekaduwa Agrarian Research and Training Institute, Colombo. 